Article

\title{
Exergy as a Useful Variable for Quickly Assessing the Theoretical Maximum Power of Salinity Gradient Energy Systems
}

\section{Raynald Labrecque}

Institut de Recherche d'Hydro-Québec, Laboratoire des technologies de l'énergie, 600 de la Montagne ave, Shawinigan, Quebec G9N 7N5, Canada; E-Mail: labrecque.raynald@lte.ireq.ca

Received: 14 September 2009 / Accepted: 3 November 2009 / Published: 5 November 2009

\begin{abstract}
It is known that mechanical work, and in turn electricity, can be produced from a difference in the chemical potential that may result from a salinity gradient. Such a gradient may be found, for instance, in an estuary where a stream of soft water is flooding into a sink of salty water which we may find in an ocean, gulf or salt lake. Various technological approaches are proposed for the production of energy from a salinity gradient between a stream of soft water and a source of salty water. Before considering the implementation of a typical technology, it is of utmost importance to be able to compare various technological approaches, on the same basis, using the appropriate variables and mathematical formulations. In this context, exergy balance can become a very useful tool for an easy and quick evaluation of the maximum thermodynamic work that can be produced from energy systems. In this short paper, we briefly introduce the use of exergy for enabling us to easily and quickly assess the theoretical maximum power or ideal reversible work we may expect from typical salinity gradient energy systems.
\end{abstract}

Keywords: exergy; salinity gradient energy systems; electric power

\section{Introduction}

It is known that mechanical work, and in turn electricity, can be produced from a difference in the chemical potential that may result from a salinity gradient. Such a gradient may be found, for instance, in an estuary where a stream of soft water is flooding into a sink of salty water that we may find in an ocean, gulf or salt lake. Various technological approaches, still under development, are proposed for the production of electric power out of a salinity gradient between a stream of soft water and a source of 
salty water. One of the technologies being intensively studied and experimented is called Pressure Retarded Osmosis (PRO). This technology relies on the use of water permeable membranes to pressurize a stream of salt water by osmotic permeation of water through the membranes, enabling this pressurized stream to be used for the production of mechanical work through the use of a hydraulic turbine (see references [1-10]). Another technology that is examined is called Reversed ElectroDialysis (RED), which relies on salt ionic diffusion from a concentrated stream to a dilute stream, through the use of selective ionic membranes [11-14]. The transport of ions through the ionic membranes allows the production of a continuous current (DC) at a given voltage, thus an electrical power. Other technological approaches have been proposed or experimented $[15,16]$, but it is beyond the scope of this paper to present and describe all the technological approaches proposed for the production of energy from salinity gradients.

Before considering implementation of a technology for a specific application related to power production from salinity gradients, it is of utmost importance to be able to compare the various technological approaches that are proposed. Such comparisons must be done on a common basis, using the appropriate variables and mathematical formulations. In this context, exergy balance could be a very useful tool for an easy and quick evaluation of the maximum thermodynamic mechanical power that can be produced from such energy systems. The scope of this paper is to briefly introduce the use of exergy for enabling us to easily and quickly calculate the maximum theoretical power we may expect from typical salinity gradient energy systems, in the perspective of simple thermodynamic. This will be illustrated with cases corresponding to ideal, reversible processes. Topics related to irreversibility for real systems are beyond the scope of this introductory article.

\section{Defining the System}

We start with the principle that it is possible to calculate the maximum power that can be produced out of a salinity gradient between two streams of different salinities. As shown in Figure 1, let us consider an open system, represented by a box, with two inlet streams of different salinities, namely streams A and B. Each of these streams is considered as composed of water (solvent) containing a dissolved solute (salt). In Figure 1, the dashed line indicates a separation or barrier between two types of compartments, each of them respectively linked to stream A and stream B. Inside the box, we consider that there is a mass exchange between the two types of compartments, such that at the outlet of the system, there are two streams, respectively A' and B'. Mass exchange is considered as two internal streams as shown in Figure 1: one describing salt transport (salt) and another defining transport of water (w).

In a system based on membrane water permeation such as PRO, the desired phenomena is osmotic transport of water from a dilute type of compartment fed by a diluted stream (stream B), to a concentrate type one fed by a concentrated stream (stream A). In the case of a technology such as RED, the desired phenomenon is ionic transport of salt from the concentrate type of compartment to the diluted type one. 
Figure 1. Schematic of a system for the production of work from a salinity gradient.

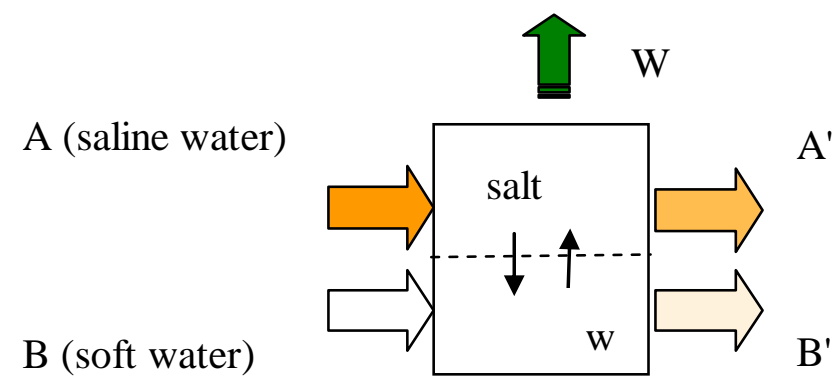

In order to calculate thermodynamically the maximum power $\mathrm{W}$ that could be produced from a system as presented in Figure 1, we must first specify each of the following:

(i) Pressure and temperature for each of streams A, A', B and B'

(ii) Mass flowrate and composition of each of the inlet streams A and B

(iii) Mass flowrate and direction of each of the internal stream describing respectively transport of water and transport of salt.

\section{Assessing Mass Balance}

The mass balance presented by Equations 1 to 4 enables us to calculate composition and flow rate, of each of the outlet streams A' and B'. The salt mass balance is described by Equations 1 and 2, while the water mass balance is described by Equations 3 and 4:

$$
\begin{gathered}
F_{A} x_{A}-\tau_{S} F_{A} x_{A}=F_{A^{\prime}} x_{A^{\prime}} \\
F_{B} x_{B}+\tau_{S} F_{A} x_{A}=F_{B^{\prime}} x_{B^{\prime}} \\
F_{A}\left(1-x_{A}\right)+\tau_{w} F_{B}\left(1-x_{B}\right)=F_{A^{\prime}}\left(1-x_{A^{\prime}}\right) \\
F_{B}\left(1-x_{B}\right)-\tau_{w} F_{B}\left(1-x_{B}\right)=F_{B^{\prime}}\left(1-x_{B^{\prime}}\right)
\end{gathered}
$$

where $F$ refers to mass flowrate $(\mathrm{kg} / \mathrm{s})$ of a specific stream, x is the mass fraction of salt in a specific stream, $\tau_{s}$ is the fraction of salt in stream A transferred to steam B', and $\tau_{w}$ is the fraction of water in stream B transferred to stream A'. For fixed or known values of $\tau_{s}, \tau_{w}, F_{A}, F_{B}, x_{A}$ and $x_{B}$, composition and flow of each of the exit streams A' and B' can then be calculated.

\section{Assessing the Exergy Balance}

With the mass balance values, we can then calculate the theoretical thermodynamic power resulting from the internal exchange of matter of the system, without any consideration of the design of the energy system, using a simple exergy balance. The thermodynamic power of a system as presented in Figure 1 can be easily calculated by Equation 5:

$$
W=E_{\text {in }}-E_{\text {out }}
$$


Where $E_{\text {in }}$ is the total inlet exergy flow $(\mathrm{J} / \mathrm{s})$ and $E_{\text {out }}$ is the total outlet exergy flow. Starting from known value of specific exergy for each of the four streams A, A', B and B', Equation 5 becomes:

$$
W=\left(F_{A} e_{A}+F_{B} e_{B}\right)-\left(F_{A^{\prime}} e_{A^{\prime}}+F_{B^{\prime}} e_{B^{\prime}}\right)
$$

Where $F$ is the mass flow rate $(\mathrm{kg} / \mathrm{s})$ of a specific stream and $e$ is to the specific exergy $(\mathrm{J} / \mathrm{kg})$ of a given stream.

Exergy is a thermodynamic state variable introduced as a measure of the capability of a stream to produce useful work [17]. It is the maximum work that can be produced when this stream is at equilibrium with a reference environment. Since we deal with streams characterized by their temperature, pressure and salinity, a reference state for liquid streams could stand for a stream of pure water (salinity zero) at a reference temperature of $0{ }^{\circ} \mathrm{C}$ and atmospheric pressure $(1 \mathrm{~atm})$ with the reference state for salt being an infinitely dissolved solution. For a system where kinetic and gravitational energy are to be accounted, the reference state could also include a reference height of zero and a stream velocity of zero. At reference conditions, specific exergy of a stream is zero.

Total mechanical specific exergy (relative to a reference state) of a given stream can be calculated from Equation 7:

$$
e=e_{t}+e_{k}+e_{z}+e_{c h}
$$

where $e_{t}$ is the specific thermomechanical exergy, $e_{k t}$ is the specific kinetic exergy (equal to specific kinetic energy), $e_{z}$ is specific gravitational exergy (equal to specific gravitational potential energy) and $e_{c h}$ is the chemical exergy. For saline solutions for which thermodynamic properties such as enthalpy and entropy are known, Equation 8 can be used, where $h$ is the specific enthalpy of the stream $(\mathrm{J} / \mathrm{kg}), s$ is the specific entropy of the stream $(\mathrm{J} / \mathrm{kg}-\mathrm{K}), T_{0}$ is the reference absolute temperature (ex: $\left.273 \mathrm{~K}\right)$, with $h_{0}$ and $s_{0}$ as enthalpy and entropy of the reference state respectively. Kinetic and gravitational exergies are to be calculated with Equations 9 and 10 respectively, where $v$ is the velocity of the fluid $(\mathrm{m} / \mathrm{s})$, and $Z$ is a given height $(\mathrm{m})$ and $g$ is the gravitation constant $\left(9.807 \mathrm{~m} / \mathrm{s}^{2}\right)$ :

$$
\begin{gathered}
e_{t}+e_{c h}=\left(h-h_{0}\right)-T_{0}\left(s-s_{0}\right) \\
e_{k}=\left(\frac{1}{2} v^{2}\right) \\
e_{Z}=Z g
\end{gathered}
$$

In the case of a membrane system involving a low fluid velocity (ex: below $1 \mathrm{~m} / \mathrm{s}$ ), kinetic exergy can be neglected, and where height is of no concern or of low value (ex: below $1 \mathrm{~m}$ ), potential exergy is to be neglected also. Total exergy of a stream can then simply be calculated from Equation 8 .

Setting $h_{0}$ and $s_{0}$ to zero, Equation 8 reduces to Equation 11

$$
e_{t, j}+e_{c h, j}=h_{j}-T_{0} s_{j}
$$

where subscript $\mathrm{j}$ refers to a specific stream i.e., $\mathrm{A}, \mathrm{B}, \mathrm{A}^{\prime}$ or B'. According to this equation, we only need $h_{i}$ and $s_{i}$ to calculate the specific exergy of a stream $\mathrm{j}$, each of these variables being function of temperature, pressure and composition of the stream. For the general case of non-ideal mixture such as concentrated brines, values of specific enthalpy and specific entropy of a stream can be obtained from 
the literature (tables, empirical equations, etc.), or one may use commercial software. Many commercial process simulators are well equipped with activity coefficient models allowing the calculation of thermodynamic properties such as enthalpy and entropy of electrolytes. Equation 11 can then straightforwardly be applied to obtain the thermomechanical and chemical exergy of a stream.

\section{Examples}

\subsection{Presentation of the examples and methodology}

Based on the methodology described above, we can easily figure out the maximum mechanical work (and then electricity) that can be produced from a difference in the chemical potential that may result from a salinity gradient between a stream of soft water (stream B in Figure 1) and a stream of salty water (stream A in Figure 1). Three situations (case studies) describing open systems are briefly examined here. The parameters used for calculations are presented in Table 1. One case refers to a general system involving the mixing of $1,000 \mathrm{~kg} / \mathrm{s}$ of soft water with a infinite sink of oceanic water, another one refers to a device involving water transport through a physical barrier (semi-permeable membrane) such as a PRO type system, and the last case refers to a system involving salt transport (through a set of ionic membranes) such as a RED type system. For each of the three cases, temperature is fixed at $10{ }^{\circ} \mathrm{C}$ and pressure at $1 \mathrm{~atm}$. It should be emphasized here that the cases correspond to ideal reversible processes, not real ones.

For a simple an easy evaluation of $h$ and $s$ (relative to values at reference state set to zero) of oceanic saline water, and for the purpose of the calculations related to the case studies presented here, we use the following equations proposed by Millero et al. [18]):

$$
\begin{gathered}
h=A_{H} \xi+B_{H} \xi^{3 / 2}+C_{H} \xi^{2} \\
A_{H}=3.4086 \times 10^{-3}-6.3798 \times 10^{-5} \theta+1.3877 \times 10^{-6} \theta^{2}-1.0512 \times 10^{-8} \theta^{3} \\
B_{H}=7.9350 \times 10^{-4}+1.0760 \times 10^{-4} \theta-6.3923 \times 10^{-7} \theta^{2}+8.60 \times 10^{-9} \theta^{3} \\
C_{H}=-4.7989 \times 10^{-4}+6.3787 \times 10^{-6} \theta-1.1647 \times 10^{-7} \theta^{2}+5.717 \times 10^{-10} \theta^{3} \\
S=A_{S} \xi+B_{S} \xi^{3 / 2}+C_{S} \xi^{2} \\
A_{S}=1.42185 \times 10^{-3}-3.1137 \times 10^{-7} \theta+4.2446 \times 10^{-9} \theta^{2} \\
B_{S}=-2.1762 \times 10^{-4}+4.1426 \times 10^{-7} \theta-1.6285 \times 10^{-9} \theta^{2} \\
C_{S}=1.0201 \times 10^{-5}+1.5903 \times 10^{-8} \theta-2.3525 \times 10^{-10} \theta^{2}
\end{gathered}
$$

where $\xi$ is the salinity (part per thousand) of a specific stream (expressed as g of solute salt per $\mathrm{kg}$ of solution, which is equal to $1000 x$; we consider this as a good approximation, but according to Millero, total grams of salt per $\mathrm{kg}$ of seawater is salinity multiplied by 1.004880) and $\theta$ is temperature in Celsius $\left(0-40^{\circ} \mathrm{C}\right)$. 
Table 1. Parameters for the calculation of maximum power from salinity gradient for three case studies.

\begin{tabular}{|l|c|c|c|c|c|}
\cline { 2 - 5 } \multicolumn{1}{c|}{} & Units & Symbol & $\begin{array}{c}\text { General system } \\
\text { (mixing) }\end{array}$ & $\begin{array}{c}\text { PRO type } \\
\text { system }\end{array}$ & $\begin{array}{c}\text { RED type } \\
\text { system }\end{array}$ \\
\hline Mass flow-seawater (stream A) & $\mathrm{kg} / \mathrm{s}$ & $\mathrm{F}_{\mathrm{A}}$ & $\mathrm{F}_{\mathrm{A}}>>\mathrm{F}_{\mathrm{B}}$ & 1,000 & 1,000 \\
Salinity-stream A & $\mathrm{g} / \mathrm{kg}$ & $\xi_{\mathrm{A}}$ & 35 & 35 & 35 \\
Mass flow-soft water (stream B) & $\mathrm{kg} / \mathrm{s}$ & $\mathrm{F}_{\mathrm{B}}$ & 1,000 & 1,000 & 1,000 \\
Salinity-stream B & $\mathrm{g} / \mathrm{kg}$ & $\xi_{\mathrm{B}}$ & 0 & 0 & 0 \\
Salt transfer ratio from A to B & & $\tau_{s}$ & 0 & 0 & variable \\
Water transfer ratio from B to A & & $\tau_{w}$ & $\rightarrow 1$ & variable & 0 \\
Temperature & ${ }^{\circ} \mathrm{C}$ & $\theta$ & 10 & 10 & 10 \\
Pressure & $\mathrm{atm}$ & $\mathrm{p}$ & 1 & 1 & 1 \\
Calculated maximum power & $\mathrm{kW}$ & $\mathrm{W}$ & 2,341 & figure & figure \\
\hline
\end{tabular}

\subsection{First example: system allowing transfer of pure water into a sink of oceanic water}

In the first situation, we calculate the maximum power that can be recovered from a system (or device) involving the transfer of $1,000 \mathrm{~kg} / \mathrm{s}$ of pure water (salinity zero) to a sink of oceanic water with a salinity of $35 \mathrm{~g} / \mathrm{kg}$. We suppose $F_{A} \gg F_{B}$ in the mass balance calculations. Fixing $\tau_{w}$ at a value close to 1 means that $F_{B}$, will become close to zero according to Equation (4). As shown in Table 1, calculated maximum power is $2,341 \mathrm{KW}$ or $2,341 \mathrm{~kJ}(0.65 \mathrm{kWh})$ per $1,000 \mathrm{~kg}$ of fed soft water (inlet stream B). This is equivalent to a gravitational potential energy corresponding to a height of $239 \mathrm{~m}$ according to Equation 10, or a kinetic energy corresponding to a velocity of $68 \mathrm{~m} / \mathrm{s}$ according to Equation 9.

Figure 2. Variation of theoretical reversible power with water transfer ratio (PRO type system) or salt transfer ratio (RED type system).

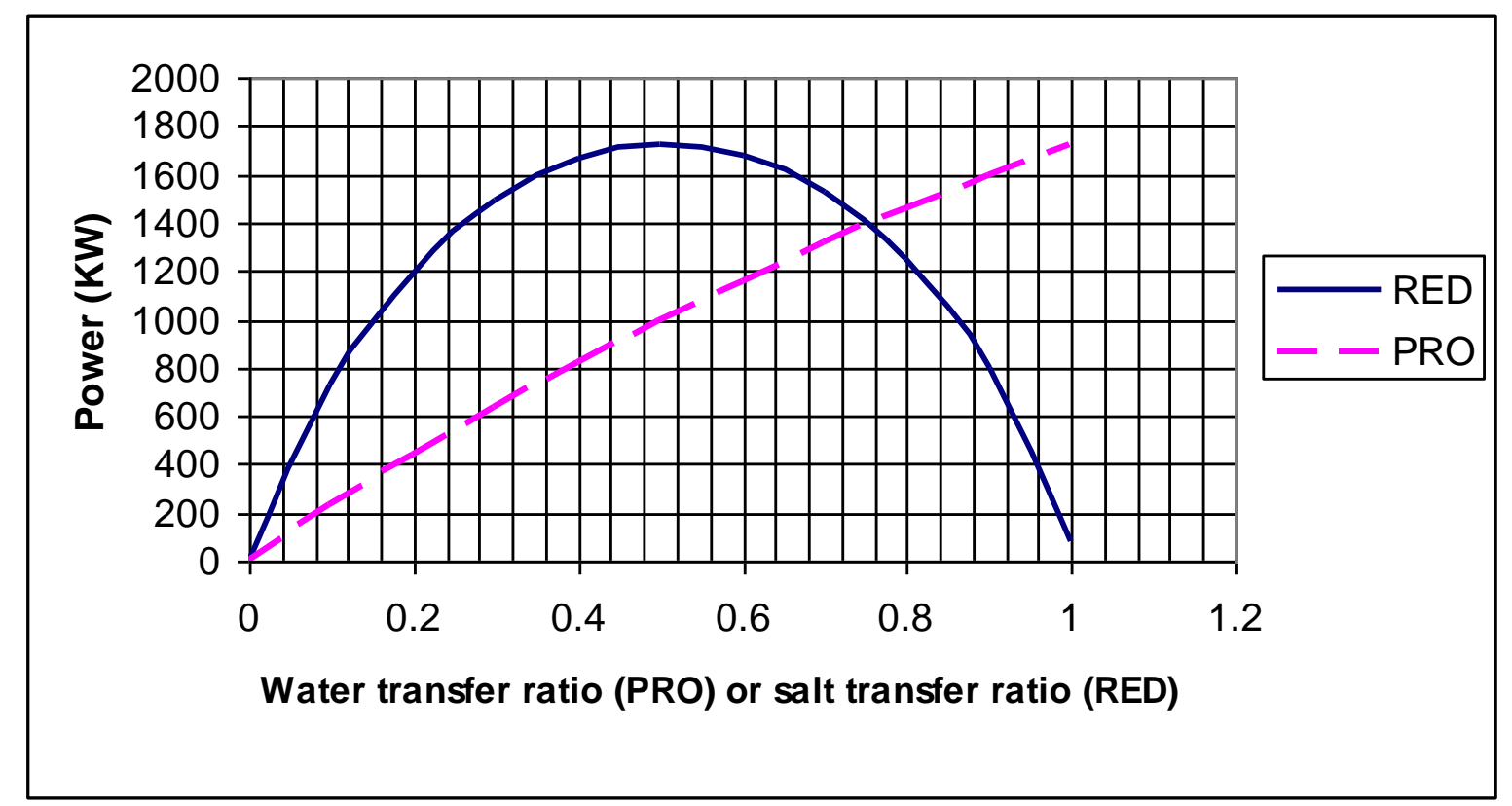




\subsection{Second example: a PRO type system}

We consider the situation of a membrane based system for which flow of each of the inlet streams A and $\mathrm{B}$ is $1,000 \mathrm{~kg} / \mathrm{s}$ as presented in Table 1 . We consider the ideal situation of no transport of salt $\left(\tau_{s}=0\right)$ Figure 2 shows the effect of $\tau_{w}$ on the power. Table 2 shows calculated values of $h, s$ and $e_{t}+e_{c h}$ for stream A' for different values of $\tau_{w}$, as intermediary results. Value of exergy is zero for streams B and B' (pure water). Enthalpy and entropy for stream A are equal to the corresponding variables for stream A' when $\tau_{w}$ is zero. We can see from Figure 2 that, in this case, a higher recovery of water will allow a higher mechanical power. For a practical water recovery rate of 0.8 we have $1,458 \mathrm{KW}$ or $1,458 \mathrm{~kJ}(0.405 \mathrm{kWh})$ per $1,000 \mathrm{~kg}$ of inlet stream $\mathrm{B}$.

Table 2. Calculated values of specific enthalpy, entropy and exergy of stream A', for different values of $\tau_{w}$ (PRO type ideal system).

\begin{tabular}{cccc}
\hline $\boldsymbol{\tau}_{\boldsymbol{w}}$ & $\begin{array}{c}\boldsymbol{h} \\
(\mathbf{1 0 0} \mathbf{~ k J} / \mathbf{k g})\end{array}$ & $\begin{array}{c}\boldsymbol{s} \\
(\mathbf{1 0 0} \mathbf{~ J J} / \mathbf{k g}-\mathbf{K})\end{array}$ & $\begin{array}{c}\boldsymbol{e}_{\boldsymbol{t}}+\boldsymbol{e}_{\boldsymbol{c h}} \\
(\mathbf{k J} \mathbf{k g})\end{array}$ \\
\hline 0 & -4.6184 & 1.8096 & -5.1673 \\
0.1 & -1.4631 & 1.7276 & -4.9037 \\
0.2 & 0.6918 & 1.6533 & -4.6720 \\
0.3 & 2.1841 & 1.5856 & -4.4653 \\
0.4 & 3.2258 & 1.5234 & -4.2791 \\
0.5 & 3.9543 & 1.4662 & -4.1098 \\
0.6 & 4.4612 & 1.4133 & -3.9549 \\
0.7 & 4.8088 & 1.3642 & -3.8125 \\
0.8 & 5.0408 & 1.3185 & -3.6809 \\
0.9 & 5.1877 & 1.2759 & -3.5589 \\
$\rightarrow 1$ & 5.2719 & 1.2361 & -3.4454 \\
\hline
\end{tabular}

\subsection{Second example: RED type system}

In this last example, we consider the situation of a membrane based system for which flow of each of the inlet streams is $1,000 \mathrm{~kg} / \mathrm{s}$ as presented in Table 1 . We consider ideal case where there is no transport of water $\left(\tau_{w}=0\right)$ Figure 2 shows the effect of $\tau_{s}$ on the power. Table 3 shows calculated values of $h, s$ and $e_{t}+e_{c h}$ for each of the outlet streams A' and B', for different values of $\tau_{s}$, as intermediary results. Value of exergy is zero for streams B (pure water). Enthalpy and entropy for stream $\mathrm{A}$ are equal to the corresponding variables for stream A' when $\tau_{s}$ is zero.

We can see that in this case, there is an optimum of $1,723 \mathrm{~kW}$ for a salt recovery rate of 0.5 . Such an optimum is to be expected since an increase in the transport rate of salt transport will involve simultaneously an increase in the salinity of stream B' and a decrease in the salinity of stream A, meaning a decrease in the global salinity gradient in the system. For a practical salt recovery rate of 0.3 we have $1,488 \mathrm{KW}$ or $1,488 \mathrm{~kJ}(0.413 \mathrm{kWh})$ per $1,000 \mathrm{~kg}$ of inlet stream B. 
Table 3. Calculated values of specific enthalpy, entropy and exergy of streams A' and B' for different values of $\tau_{s}$ (RED type ideal system).

\begin{tabular}{c|ccc|ccc}
\hline Streams $\rightarrow$ & \multicolumn{3}{|c|}{$\mathbf{A}^{\prime}$} & \multicolumn{3}{c}{$\mathbf{B}^{\prime}$} \\
$\tau_{s}$ & $\begin{array}{c}h \\
(100 \mathrm{~kJ} / \mathrm{kg}\end{array}$ & $\begin{array}{c}s \\
(100 \mathrm{~kJ} / \mathrm{kg}-\mathrm{K})\end{array}$ & $\begin{array}{c}e_{t}+e_{c h} \\
(\mathrm{~kJ} / \mathrm{kg})\end{array}$ & $\begin{array}{c}h \\
(100 \mathrm{~kJ} / \mathrm{kg}\end{array}$ & $\begin{array}{c}s \\
(100 \mathrm{~kJ} / \mathrm{kg}-\mathrm{K})\end{array}$ & $\begin{array}{c}e_{t}+e_{c h} \\
(\mathrm{~kJ} / \mathrm{kg})\end{array}$ \\
\hline 0 & -4.6184 & 1.8096 & -5.1673 & 0.0000 & 0.0000 & 0.0000 \\
0.1 & -1.2789 & 1.7220 & -4.8860 & 1.6731 & 0.3684 & -1.0258 \\
0.2 & 1.3734 & 1.6246 & -4.5840 & 3.2759 & 0.6449 & -1.7923 \\
0.3 & 3.3406 & 1.5154 & -4.2551 & 4.4765 & 0.8707 & -2.4192 \\
0.4 & 4.6285 & 1.3915 & -3.8918 & 5.1664 & 1.0604 & -2.9493 \\
0.5 & 5.2485 & 1.2497 & -3.4842 & 5.2896 & 1.2227 & -3.4075 \\
0.6 & 5.2204 & 1.0855 & -3.0198 & 4.8136 & 1.3634 & -3.8102 \\
0.7 & 4.5776 & 0.8929 & -2.4810 & 3.7186 & 1.4865 & -4.1696 \\
0.8 & 3.3783 & 0.6628 & -1.8418 & 1.9931 & 1.5954 & -4.4949 \\
0.9 & 1.7360 & 0.3796 & -1.0569 & -0.3693 & 1.6925 & -4.7934 \\
1 & 0.0000 & 0.0000 & 0.0000 & -3.3714 & 1.7799 & -5.0709 \\
\hline
\end{tabular}

\section{Conclusions}

From the examples presented above, we can see how easy it becomes to calculate the maximum power obtainable from a salinity gradient, using a simple exergy balance. Furthermore, since we use pure thermodynamics, it becomes possible to compare technologies or different approaches being proposed for the production of power from a salinity gradient. Nevertheless, we should keep in mind that practical performance of systems could be far from the maximum values calculated thermodynamically. Apart from any consideration related to irreversibility encountered in any system, we should mention here that, in a membrane process, the effect of concentration polarization related to mass transfer phenomena involved is known to have a detrimental effect on the performance of such systems. Evaluating maximum achievable performance using thermodynamics is useful because we already know what we can expect from a given system. This exercise can then be part of preliminary investigation for the choice of a technology for a specific application.

\section{Acknowledgements}

Thanks to Georges Houlachi for guidance in the preparation of this paper.

\section{References and Notes}

1. Loeb, S. Osmotic power plants. Science 1975, 189, 654-655.

2. Loeb, S. Production of energy from concentrated brines by pressure retarded osmosis. $J$. Membrane Sci. 1976, 1, 49-63.

3. Loeb, S. Method and apparatus for generating power utilizing pressure-retarded osmosis. US Patent 4,193,267, 1980.

4. Loeb, S. Energy production at dead sea by pressure-retarded osmosis: Challenge or chimera? Desalination 1998, 120, 247-262.

5. Loeb, S.; Honda, T.; Reali, M. Comparative mechanical efficiency of several plant configurations using a pressure-retarded osmosis converter. J. Membrane Sci. 1990, 51, 223-335. 
6. Loeb, S. Large scale production by pressure-retarded osmosis, using river water and sea water passing through spiral modules. Desalination 2002, 143, 115-122.

7. Stover, R.L.; Pique, G.G. Osmotic power from the ocean. Power 2006, 150, 76-80.

8. Panyor, L. Renewable energy from dilution of salt water with fresh water: Pressure retarded osmosis. Desalination 2006, 199, 408-410.

9. Cameron, I.B.; Clemente, R.B. SWRO with ERI's PX pressure exchanger device-a global survey. Desalination 2008, 221,136-142.

10. Skilgahen, S.E.; Dugstad, J.E.; Aaberg, R.J. Osmotic power-power production based on osmotic pressure difference between waters with varying salt gradients. Desalination 2008, 220, 476-482.

11. Post, J.W.; Veerman, J.; Hamelers, H.V.M.; Euverink, G.J.W.; Metz, S.J.; Nymeijer, K.; Buisman, C.J.N. Salinity-gradient power: Evaluation of pressure-retarded osmosis and reverse electrodialysis. J. Membrane Sci. 2007, 288, 218-230.

12. Weinstein, J.N.; Leitz, F.B. Electric power from differences in salinity: The dialytic battery. Science 1976, 191, 557-559.

13. Lacey, R.E. Energy by reverse electrodialysis. Ocean Energy 1980, 7, 1-47.

14. Turek, M.; Bandura, B. Renewable energy by reverse electrodialysis. Desalination 2007, 205, 67-74.

15. Jones, A.T.; Finley, W. Recent developments in salinity gradient power. Oceans 2003, 4, 2284-2287.

16. Olson, M.; Wick, G.L.; Isaacs, J.D. Salinity gradient power: Utilizing vapour pressure differences. Science 1979, 206, 452-454.

17. Labrecque, R.; Boulama, K.G. Get the most out of waste heat. Chem. Eng. 2006, 11, 40-43.

18. Millero, F.J.; Leung, W. The thermodynamics of seawater at one atmosphere. Amer. J. Sci. 1976, 276, 1035-1077.

(C) 2009 by the authors; licensee Molecular Diversity Preservation International, Basel, Switzerland. This article is an open-access article distributed under the terms and conditions of the Creative Commons Attribution license (http://creativecommons.org/licenses/by/3.0/). 